\title{
PI3K-delta Inhibitor AMG 319
}

National Cancer Institute

\section{Source}

National Cancer Institute. PI3K-delta Inhibitor AMG 319. NCI Thesaurus. Code C95891.

A highly selective, potent, and orally bioavailable small molecule inhibitor of the delta isoform of the $110 \mathrm{kDa}$ catalytic subunit of class IA phosphoinositide-3 kinases (PI3K) with potential immunomodulating and antineoplastic activities. PI3K-delta inhibitor AMG 319 prevents the activation of the PI3K signaling pathway through inhibition of the production of the second messenger phosphatidylinositol-3,4,5-trisphosphate (PIP3), thus decreasing proliferation and inducing cell death. Unlike other isoforms of PI3K, PI3Kdelta is expressed primarily in hematopoietic lineages. The targeted inhibition of PI3Kdelta is designed to preserve PI3K signaling in normal, non-neoplastic cells. 